Open Scientist Handbook • OSH

\title{
It's time for science to \\ admit that no scientist is a lone giant in their field
}

Bruce R. Caron

Published on: Mar 10, 2021

DOI: $10.21428 / 8 b b b 7 f 85.98220 c a e$

License: Creative Commons Attribution 4.0 International License (CC-BY 4.0). 

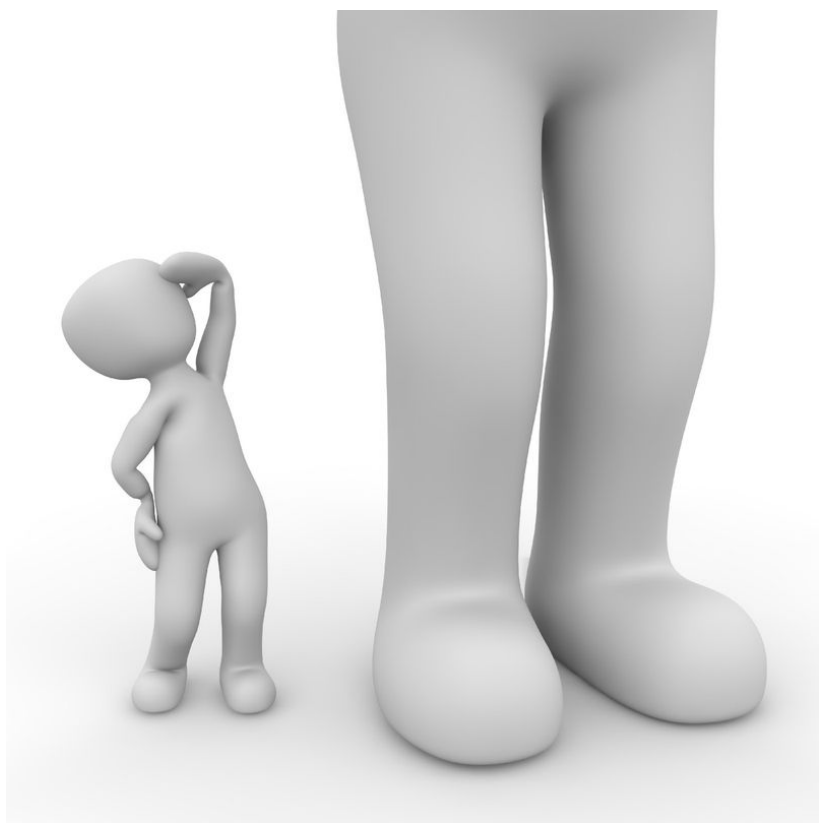

"If I have seen further it is by standing on the sholders [sic] of Giants." Isaac Newton. 1676. Letter to Robert Hooke (before they became bitter enemies). This notion was a commonplace in the $17^{\text {th }}$ Century, with the implications that even a dwarf would see further than a giant if he were standing on the giant's shoulders. (Wikipedia).

"If our team's ideas add value to the current state of knowledge, it is because we have borrowed widely and well from the abundance of prior understanding surrounding us, and climbed a stairway of knowledge built by others." Modern version... no giants.

One of the hard lessons for open science is to abandon the notion that "great" scientists -those "giants" of the academy-were and are individuals of some unique and rare quality; that their shoulders tower above those of their peers, and that the optimal career goal of a scientist is to become a giant in their field. And, if you are a woman in science, while standing on the shoulders of "giants" in the academy, you can be fairly certain that some of them would have been intent on looking up your skirt; another reason why open science needs Fierce Equality. 
In Isaac Newton, the Asshole who Reinvented the Universe (Freistetter 2018) we get a picture of Newton's brilliance as a natural philosopher, and of his serial acts of intellectual and careerist selfishness. Biographies of Newton's career and personality issues are several (See also: Clark and Clark 2001; Manuel 1979; Gleick 2004). The biographies of several of his contemporaries (Leibniz, Hooke, Gray, and Flamsteed for starters) reveal their side of the dangers of being on Newton's wrong side. But then Newton's bad behavior was not as unusual as it perhaps should have been. Rather, it was distinguished by its obsessive persistence, and made potent by Newton's position at the head of the Royal Society. Freistetter excused much of Newton's bad behavior as emblematic of an academy culture where intellection was-and still is-a cerebral variety of blood sport. He did venture that Newton would still be called an asshole if he were working today.

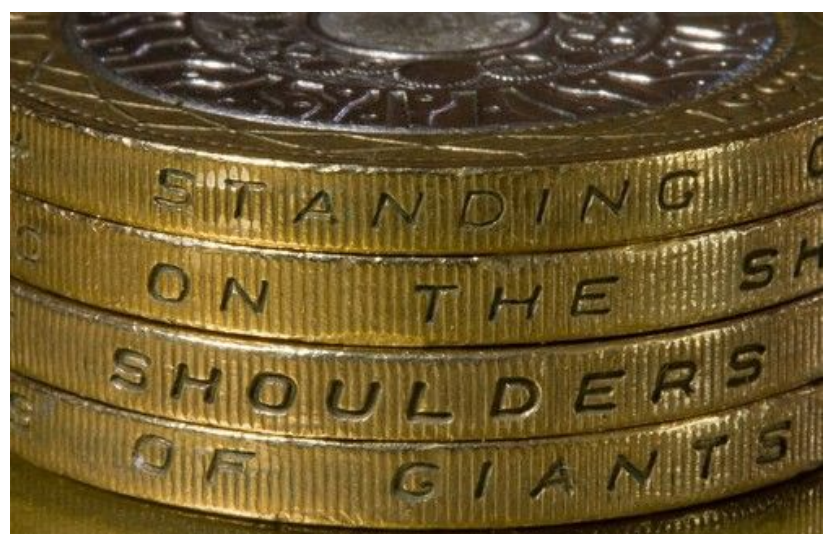

Newton's interpersonal misconduct is less of an issue here. For more on assholes, take a look at The ZeroAsshole Zone. While producing a series of astonishing research findings from his own work, Newton was soaking up ideas and credit from others, while insisting that his ideas were his alone. Apparently, we wasn't entirely serious about the whole "giant sholders" thing.

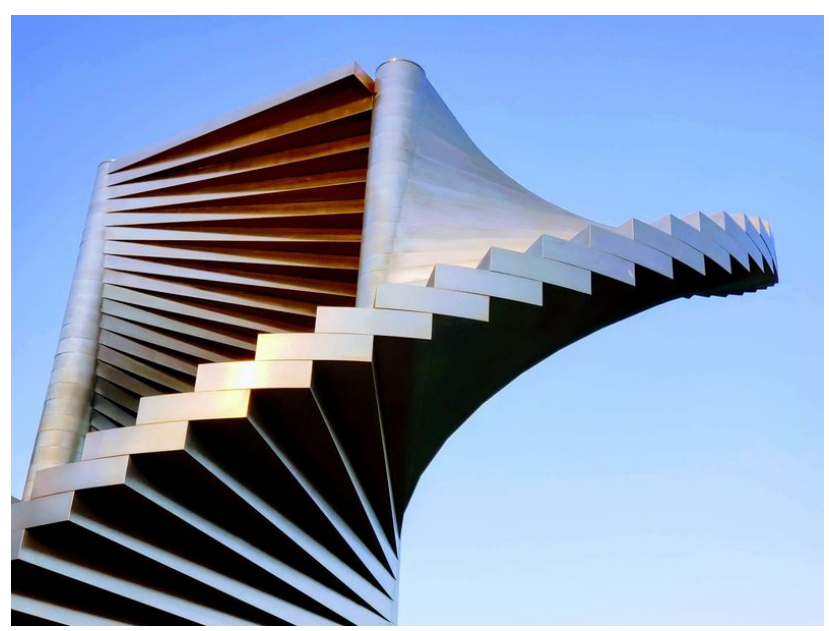

You want to get good at doing science-as a personal goal-because this leads to more satisfaction in your daily life and career, and because you can become more valuable to science by having better conversations that lead to more interesting questions and 
new ideas. You getting better at being a scientist should, in no manner, obstruct others on their path to getting better at this. In fact, one of the advantages of open work in science is that you can lift others during your climb up the same stairs. You can always grow. You can grow a larger sense of the science you are working with/on, a perception of how your work fits into the field, and appreciation for the work of your colleagues. Your primary challenge is to be better at science (and being human) today than you were yesterday.

“[B]y some measure, every important innovation is fundamentally a network affair" (Johnson 2011).

"[M]odern scholarship is based on cooperation. Ideas are not created in a vacuum. Reuse of research processes, methods and results as well as abstraction and extension should therefore represent basic values of scholarly communication. The possibility to reuse data, materials and results enables researchers and communities to learn from each other and to speed up the production of new knowledge" (Vienna Principles 2016; Accessed July 10, 2020).

\section{There's a badge for that}

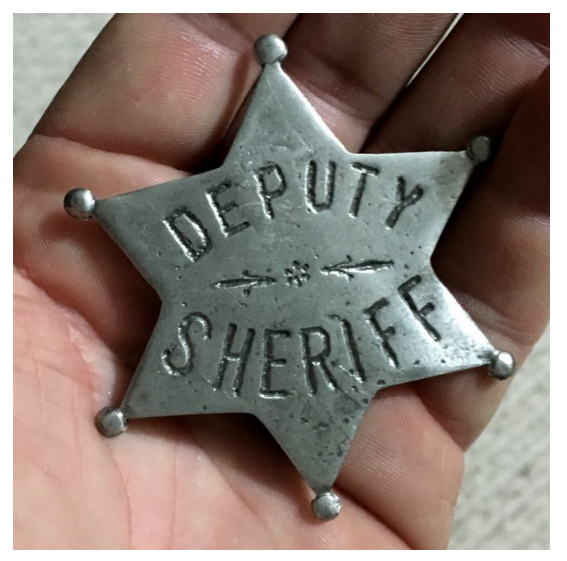

What's wrong with having and celebrating "giants" in your field? We can explore this. Firstly, the goal of exclusive achievement and individual fame requires and produces way too much scarcity in the process. In the game of "giant-making,"recognition points might need to be hoarded, reputation metrics jealously guarded, and ideas (and data) locked away until some strategic moment. Secondly, the practice of acknowledging a science giant requires the production of science dwarves. It's a zero-sum game. If nobody's small, someone can't be giant. Most giants only look large from far away because of the cumulative advantages they were given across their careers. They are standing on the shoulders of privilege. Finally, the desire to be a giant fuels narcissistic behavior, which the academy has an abundance of already.

"As Justice Louis Brandeis, who witnessed our previous Gilded Age, might have said: 'We may have democracy, or we may have praise showered on the heads of a few, but we can't have both'” (Johnson 2019: Accessed July 24, 2020) 
In a fiercely-equal, open-science culture, zero-sum games of prizes and awards handed out to would-be giants can be replaced in favor of a larger emphasis on a system of open badges that anyone can earn: with intention, time, and effort. The use of badges earned instead of prizes won for recognition of accomplishments would build a reputation economy for the academy that rewards achievement anywhere on the planet, and refocusses attention on science's generative engine: learning and community effort. "Although the edifice of scientific understanding is sometimes envisaged as an accumulation of individual discoveries, in reality science is a community effort comprising innumerable interdependent contributions. Credit is disproportionately awarded to principal investigators for what is truly the product of teamwork, and nearly all scientific contributions are heavily dependent on knowledge obtained earlier.... In the spirit of an Amish barn-raising, a celebration of the collective achievement of science should subsume individual achievement" (Casadevall and Fang $2012[\mathrm{ASM}])$.

The finite game of "making a name for oneself" in the academy is far too expensive to the academy to allow this to be a central goal of science. Science demands so much already from you: both rigor and wonder, and in generous amounts. "Science is an inherent contradiction-systematic wonder-applied to the natural world" (Lewis et al. 2001).

Because it is important to regularly celebrate open science cultural practices, and contributions to science, and to institutions, and teams, you can create honors that are playful and honest. Science doesn't need fellows in national academies as much as it needs researchers who can get honored for their dedication and their kindness. Be generous to those who are, too. Don't tell your team members to "leave their frowns at home," but hand out medals (perhaps made of chocolate) to those with the most difficulties to overcome, and the best spirit. Give away prizes every week. Cheer when someone earns a difficult badge. Turn learned society elections into lotteries, and celebrate when volunteer leaders chosen at random step up and perform. Find ways to reward as many early career colleagues as possible. In the end, you realize that everyone who makes a serious attempt to do science is already a giant. You didn't notice because you are one too. 


\section{You are automatically a member of an elite group: the club of scientists}

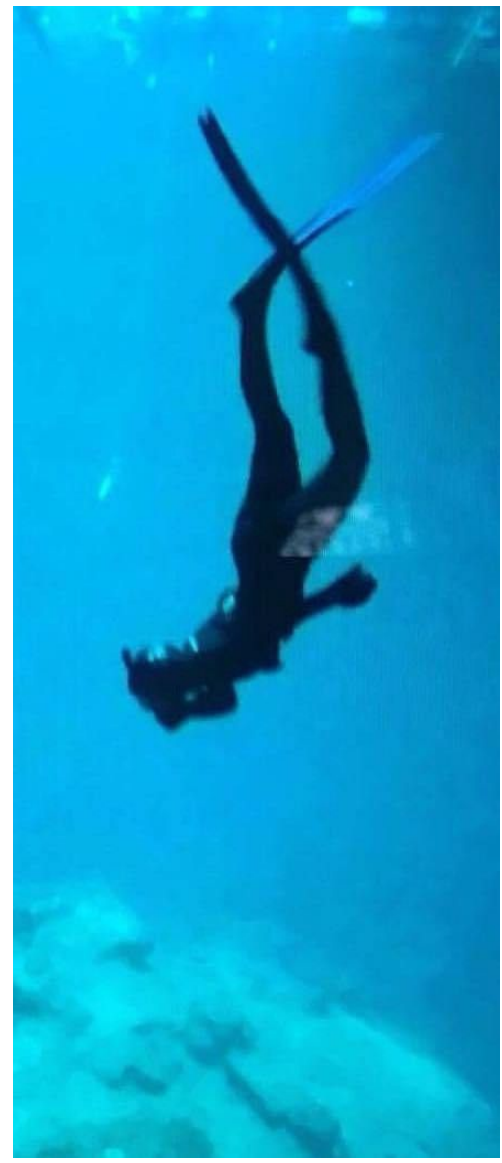

\section{Exclusivity stops you from diving deep.}

An elite cohort is a group of individuals where some special level of skilling makes these particular individuals eligible to join. An exclusive cohort is a group that has created a scarcity and manages entry. The group reserves the right to join. Private clubs can be really exclusive while not being regarded as elite (at least by others).

Free divers as a cohort can support an elite group among them without needing to consider restricting entry, without becoming exclusive. You want to be an elite free diver? Work at it. Dive deeper. Then dive even deeper. You can achieve elite status on your own.

The academy is already elite. Only about one percent of humans over the age of twenty-one have a PhD. Only a very small minority of people (with or without $\mathrm{PhDs}$ ) decide to spend vast amounts of their time exploring unknowns in the universe. This means that the academy has no need to also be exclusive. Like bullshit claims for “excellence" (Moore et al. 2017), claims for exclusivity are counter-productive. They announce that science can only be accomplished by a selected few. Selected by whom? Editors at Elsevier?

Still, within the cohort of scientists, some are known as really good scientists. These elite scientists are self-selecting. They select how much work they plan to put into doing good science.

"A central claim made by proponents of open and collaborative production is ... based on the argument that commons-based, non-proprietary systems of production are able to draw on a much wider range of human motivations than those deriving from participation in markets, or coercion by managerial command and waged labour. Benkler (2006) suggests that the freedom to co-operate in collaborative ways with others to make things of value to humans, and to be generous and kind (behaviors and patterns familiar to us from social relations generally) motivates people far more effectively and efficiently than traditional 
market mechanisms or hierarchical models of social organisation"(van Zwanenberg et al. 2017).

\section{Open science is an escalator to becoming elite.}

Open science will help you to do what you need to do to become an elite scientist: build your knowledge, your craft, and your reach. Share your research work flow so others can offer advice and kudos. Share because sharing accelerates the feedback that drives new ideas in your own work. Share because others will take your data to places you never considered.

Open science is the smart way to become elite. Be elite not through some erzatz "journal impact factor" but by sharing your work openly, and by being generous with your colleagues, particularly those few who are struggling with the same object of study you have chosen.

You and a handful of other scientists have somehow been drawn to the same problem, the same phenomenon. Together you can dive deeper into this problem than you can ever go alone. The only impact factor you need is the one that comes in your inbox from a colleague thanking you for solving one of their research pain points.

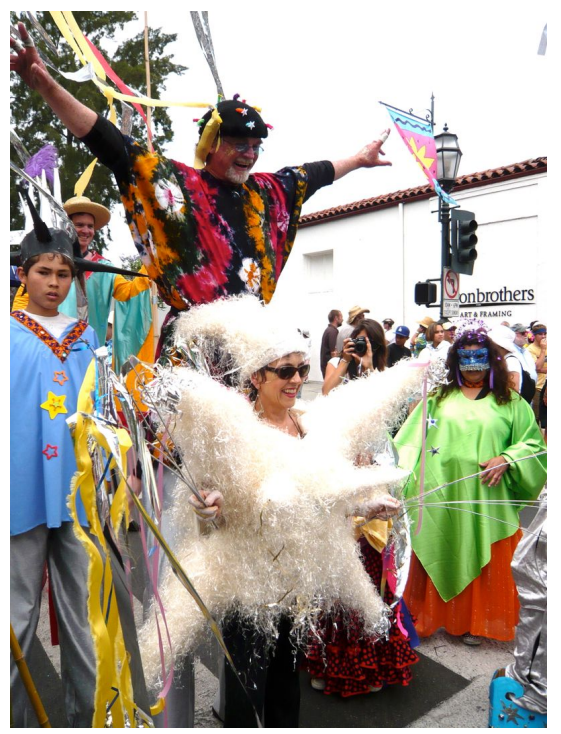

Marc McGinnes, who taught for decades at UC Santa Barbara, puts on stilts every year to become an "occasional giant."
Afterthoughts: If you still want to be a giant, be a giant for your family, be a giant in your town. Perhaps there used to be giants, back when the only way to fund science was to attract the attention and the purse of a king. If the person paying your rent is named de'Medici, perhaps you should get used to wearing stilts, just ask Galileo Galilei. The main lesson of that famous "standing on the sholders of giants" quote is that if you are going to be a life-long jerk, pop some really nice sentiments on your blog that people might remember you by three hundred years later. Even then, someone will write a book about what an asshole you were.

\section{Bibliography: Open Scientist Handbook $\underline{\text { References }}$}

